\title{
Project Maths and the Non-Cognitive Domain - The Perceptions of a group of Engineering Students in one Institute of Technology
}

\author{
Louise Duggan, Pamela Cowan, Ian Cantley \\ Queen's University, Belfast
}

\begin{abstract}
Following the publication of the Irish Leaving Certificate results in 2005, substantial concern was raised in relation to the poor mathematics results. As a result of this, the National Council for Curriculum and Assessment (NCCA) conducted a review of post primary mathematics education in Ireland [1]. Of particular concern highlighted in this review was the low level of mathematical skills attained by students emerging from post-primary school. Many students proceeding to higher education were ill-equipped to deal with the mathematical demands of their higher education discipline and generally displayed poor attitudes towards mathematics [1]. As a result of these concerns the Project Maths curriculum was proposed.

This paper reports the salient points of a preliminary study completed in March 2016 at a higher education institution in Ireland. A questionnaire was administered to a group of first year engineering students to determine the impact of Project Maths on the affective domain. The researchtested Attitudes Towards Mathematics Inventory (ATMI) was the instrument adopted in this study. A scale was also included to measure students' experiences of teaching practices which provided an indication of the extent to which the post-primary teachers are adopting and implementing the Project Maths curriculum. Several open-ended questions followed the questionnaire in order to gain an understanding of student experiences of Project Maths. Results indicate that while Project Maths did not improve all of the students' attitudes towards mathematics - at least in terms of students enjoying mathematics more - it did reveal almost every student saw mathematics as useful in the real world.
\end{abstract}

\section{Introduction}

The inception of Project Maths in Ireland arose from the difficulties identified with mathematics instruction over the years [2]. Particular concerns suggested that students were demonstrating a lack of understanding of basic mathematical constructs and the inability to apply mathematics to unfamiliar contexts [3]. These concerns inevitably have repercussions for students as they progress to higher level education and [3] in particular highlighted the observations of higher education lecturers regarding the skills gap of incoming higher level students and their inability to apply mathematics except in the most simple or practised way. Also highlighted was the traditional learning environments and the over reliance of rote learning practices to the detriment of understanding and application to problem solving [1]. Other concerns highlighted in this report include Ireland's poor performance in PISA (2000 and 2003), the low number of students opting for Honours mathematics and poor attitudes towards mathematics in general.

The aim of Project Maths was therefore to develop and enhance student understanding of key mathematical concepts, develop mathematical skills, and allow the student to apply the knowledge and skills in familiar and unfamiliar contexts by employing examples which may be familiar to the student [2]. A defining feature of the Project Maths curriculum is that it uses an investigative approach to learning mathematics, placing the learner in the centre, and therefore the learner must become an active participant in the development of their own mathematical skills and knowledge. Project Maths therefore aims to promote a more informal approach to teaching and learning mathematics. In contrast to the traditional rote learning approach to teaching mathematics, Project Maths attempts to foster in all learners a concrete understanding of mathematics.

Teaching practices advocated by the introduction of Project Maths include real world problem solving, communication within the classroom, investigations with fellow students, teamwork and a change in role of the teacher from transmitter of knowledge to facilitator of learning [1]. One of the primary objectives of Project Maths is to develop in all leaners' the ability to apply their mathematical knowledge and skills to solve problems in familiar and in unfamiliar contexts. In order for the learner to solve problems presented in unfamiliar contexts, they need to be engaged with the mathematics in question. Engaging students in learning mathematics is considered an important aspect of the Project Maths curriculum and in doing so can foster positive attitudes to mathematics in all learners [1]. Project Maths is a student centred approach to learning in which the teacher is no longer a content expert responsible for transmitting knowledge and facts to the students as in the traditional classroom, but is now viewed as a facilitator of learning, guiding the learning process. Rather than supplying the learner 
with the correct answer which can inhibit students' learning, the teacher can enhance the reasoning ability of their students by encouraging them to express their own ideas. The learners have to assume greater responsibility for their own learning and the teacher takes an active role in directing and guiding the learners in how to solve the problems presented. The teacher as the facilitator actively engages with the learners while they work on problems, by asking them questions and probing their thinking.

The Project Maths curriculum is therefore based on an approach that amalgamates elements of constructivism with elements of Realistic Maths Education (RME). Freudenthal introduced the idea of Realistic Mathematics Education (RME) as a result of his dissatisfaction with mathematics education in the 1950's which viewed mathematics as an abstract body of knowledge. Freudenthal viewed mathematics as a human activity influenced by cultural and societal factors and embedded in realistic situations. Learners are expected to actively participate in the learning environment and sensemaking forms the basis in designing the teaching and learning processes to be adopted in the classroom [4]. As well as increasing mathematical achievement for all learners, it was envisaged that Project Maths would improve their higher order thinking skills such as the ability to think logically and reason mathematically. It was also claimed that the Project Maths curriculum would improve student attitudes towards the subject and increase mathematical preparedness for higher education [2]. The Irish government also envisioned that the introduction of Project Maths would increase the number of students opting to study the subject at higher level. The uptake for higher level mathematics prior to the introduction of Project Maths was $18 \%$ and the government hoped that this would increase to $30 \%$ [1].

The introduction of Project Maths has not been without controversy, one of the main concerns is the terminology used in presenting the questions, and some teachers argue that questions seem to test literacy as well as mathematical skills [21]. This can seriously hinder students' where English is not their first language or those who suffer from dyslexia. Another flaw identified with the Project Maths curriculum is the poor balance of topics; some academics argue that there is too much emphasis on commercial mathematics such as probability and statistics and not enough on calculus and algebra [22]. Leading academics argue that this particular flaw with the Project Maths curriculum will lead to a lowering of mathematical standards, and will leave students unprepared for careers in the areas of Science, Technology Engineering and Maths (STEM) [22]. Especially noteworthy with the Project Maths curriculum is the substantial reduction in calculus, which is considered one of the pillars of mathematics and is deemed essential for anyone wishing to pursue a career as a scientist or an engineer. Linear algebra has also disappeared from the curriculum; this, in spite the fact that matrices, vectors and their associated rich and powerful theory are ubiquitous throughout engineering, physics, chemistry and computer science to name just a few applications.

\section{Constructivist learning environment}

Constructivism is an epistemology that offers an explanation as to how we learn. It is important to point out that although it can influence teaching, it is not a theory of teaching, but a theory of learning. The challenge therefore, is how to translate this theory of learning into one which can be employed in teaching. Emergent constructivist theories suggest that humans generate knowledge based on prior experiences and how they interact with others. In the constructivist classroom, the learner must play an active role in the learning process in an environment that supports him/her. Learning activities typically associated with constructivism include active engagement, inquiry, problem solving and collaboration with others. The main activity in a constructivist classroom is solving problems. Students use inquiry methods to ask questions, investigate a topic, and use a variety of resources to find solutions. As students explore the topic in greater detail, they draw conclusions, and, as exploration continues, they revisit those conclusions. Exploration of questions leads to more questions.

There is a great deal of overlap between a constructivist and social constructivist classrooms, with the exception of the greater emphasis placed on learning through social interaction with the latter. In social constructivist classrooms collaborative learning is a process of peer interaction that is mediated and structured by the teacher. Discussion can be promoted by the presentation of specific concepts, problems or scenarios, and is guided by means of effectively directed questions, the introduction and clarification of concepts and information, and references to previously learned material. In adopting a constructivist approach to teaching and learning mathematics, the teacher must focus on meaning and understanding and encourage independence, autonomy and self-direction [5].

However, as [6] explain establishing a classroom learning environment based upon constructivist learning theory can be difficult. In particular [6] stated that: 'Tasks with higher level cognitive demands increase the pupils' risk and the ambiguity involved in engagement and thus alter the commonly established exchange rate in classrooms - that of an exchange of tangible rewards for tangible products. Pupils like to know where they stand. For this reason, tasks demanding higher order thought 
processes are resisted or subverted by pupils. Resistance puts co-operation at risk. Teachers are lured into or connive at subversion and higher-level task demands are frequently re-negotiated in the direction of routine procedures' (p. 21).

There are a number of factors which can influence the implementation of the constructivist philosophy by teachers [7]. When education is driven by significant focus on results and achievement and educational conservatism, adopting constructivist principles can be difficult. Since traditional methods normally deliver results, educational systems can be slow to change. However, there are compelling arguments in favour of constructivist approaches and [8] claimed that 'the most conspicuous psychological influence on curriculum thinking in science since 1980 has been the constructivist view of learning' ( $p$. 801).

Becoming a constructivist teacher can be a difficult transformation, since most teachers have been prepared for teaching using the traditional, behaviorist approach. Becoming a constructivist teacher requires the teacher to assume a new identity, which essentially involves a paradigm shift, the teacher is no longer a 'guide on the side' but is now a facilitator of learning. This involves considerable personal change for teaching personnel. The teachers' professional practice must adapt to include the capacity to facilitate teamwork, collaborative inquiry, scaffold students' knowledge and assist students' to scaffold knowledge together. The classroom learning environment must also be transformed to a knowledge creating environment which fosters questioning and inquiry. The learners must also assume a new identity, they are no long passive recipients of knowledge; the learner must become actively involved in the process of building and transforming knowledge. In order for the learner to construct meaning, they must strive to make sense of new experiences, and in doing so must relate it to what is already known or believed about the topic. The learners develop knowledge through an active construction process and not through the passive reception of knowledge.

\section{Attitudes towards mathematics}

There is increasing recognition that as well as cognitive factors, affective factors play an important role in the teaching and learning of mathematics [9]. While the definition of attitude tends to vary in the literature, attitude can be regarded as a learned response to a situation or object which can be either positive or negative [10]. Quite often terms such as enjoyment, motivation, confidence, feelings and beliefs are used when discussing attitudes and are said to have an influence on participation rates of the learner [11]. The affective domain is multidimensional and [11] recognized the existence of three dimensions: attitudes, beliefs and emotions. These affective factors together with self-efficacy, confidence and self-concept play an important role in students' learning of mathematics [12]. It was further stated in [13] that 'repeated emotional reactions to mathematical situations become habitual and an attitude towards mathematics develops' (p. 109).

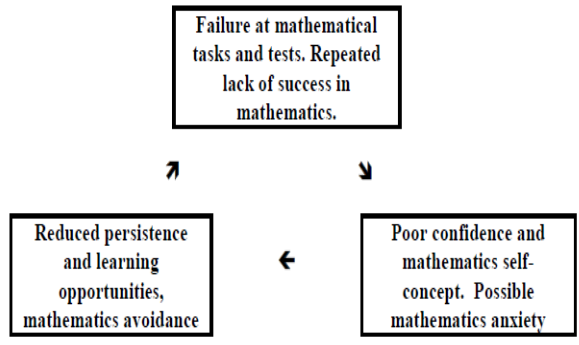

Figure 1. The failure cycle (Source: Ernest, 2013)

Figure 1 illustrates that students who experience repeated failure in mathematics tests and tasks leads to and reinforces poor confidence and poor mathematics self-concepts. If the students experience too much failure and fell humiliated at the prospect of mathematics then this can lead to mathematics anxiety in a minority of cases. In situations like this, students will go to great lengths to avoid mathematics, resulting in further failure and lack of success in mathematics [23]. Students who pursue the engineering discipline are likely to have strong overarching goals regarding success in their studies and may refuse to allow any developing negative attitudes to mathematics to impede their learning efforts. However in such circumstances their beliefs about mathematics will tend to be that it is simply a toolkit, required for their overall success.

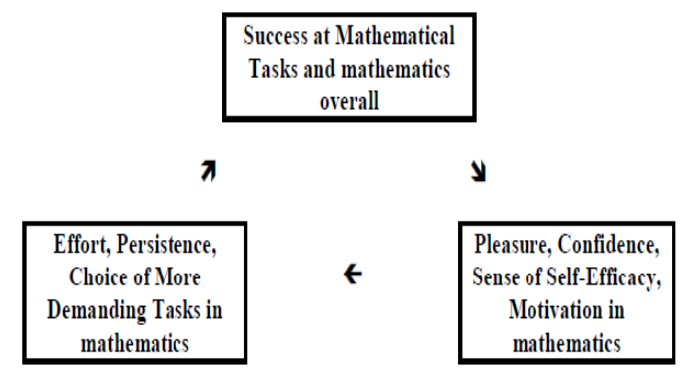

Figure 2. The success cycle (Source: Ernest, 2013)

Figure 2 illustrates that if a student experiences success at mathematical tasks, this will inevitably lead to increased pleasure and confidence, selfefficacy and motivation towards mathematics. Students are more likely to persist and be strive to be more successful mathematically [23]. Many engineering students will have a history of success and achievement in mathematics behind them as this 
is normally a pre-requisite entry requirement for many engineering courses.

Attitudes are based on prior experiences and [14] further state that student success in third level mathematics based courses is strongly correlated to their previous experience in second level education. Attitudes are defined in [15] as 'manners of acting, feeling, or thinking that show one's disposition or opinion' (p. 259). This suggests that attitudes develop from several similar and repeated emotive responses to an event or object [10]. A student's' attitude and beliefs about mathematics are also said to influence their propensity to use mathematics in future situations [10]. While a student's' cognitive competencies influence their self-confidence in mathematics, affective factors are deemed to be much better determinants of further mathematical study and participation in careers that involve mathematics [10].

In their search for a definition of attitudes towards mathematics, [16] proposed a three dimensional model for attitude (TMA) that illustrates interconnections between emotional dispositions towards mathematics, vision of mathematics and perceived competence in mathematics. The TMA model highlights the insufficiency of a positive/negative dichotomy for attitude defined as a general emotional disposition towards mathematics. Such a bipolar model as stated by [16] is too simplistic to account for complex interactions existing between beliefs and emotions in the context of mathematics. Perceived competence in mathematics is the students' perceptions of their mathematical ability and the ability to succeed in mathematics. The emotional dimension is concerned with the extent to which the students enjoys mathematics and the subject matter itself. Vision of mathematics refers to the beliefs that the student holds in relation to how important mathematics is in everyday life. The three dimensional model (TMA) is illustrated below in figure 3 .

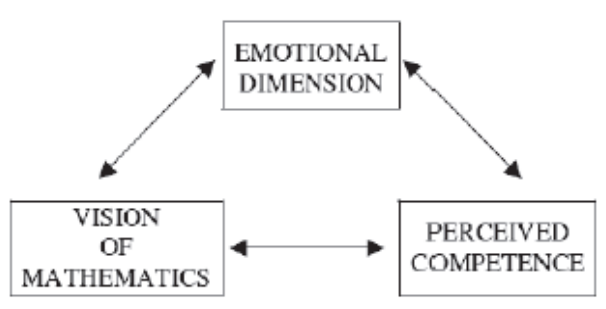

Figure 3. TMA Model for Student Attitudes (Source: Di Martino and Zan, 2010)

\section{Instrument}

There are many scales available that can measure student attitudes towards mathematics, and one which was considered was Aiken's Mathematics
Attitude Scale which was developed in 1974 [17]. Aiken claimed that attitude was multi-dimensional rather than uni-dimensional consisting of the two components, value and enjoyment of mathematics. This multi-dimensional aspect of attitude means that in order for the learner to have a positive attitude towards mathematics, they must enjoy the subject as well as have an appreciation for its value in the teaching and learning process [17]. Aiken's scale led to the development of Tapia and Marsh's Attitude Towards Mathematics Inventory (ATMI) in 1996 [17]. The original scale consisted of 49 items, however on revision this was reduced to include 40 items.

On considering the literature in relation to the affective domain and mathematics achievement, it was decided to employ a reduced version of the Attitudes Towards Mathematics Inventory (ATMI) in this preliminary study. The ATMI consists of 40 statements that measure four factors affecting student attitude including self-confidence, value, enjoyment and motivation. While the motivation scale is viewed as a component of affect, other instruments suggest that the subcomponents of affect make up motivation [17], and since motivation to learn mathematics does not feature prominently in the TMA model, it was decided to omit the 5 statements specifically relating to motivation. The ATMI has a validity of 0.97 when used with college students and the content validity has been established [18]. The survey is based on a 5-point Likert scale that ranges from Strongly Disagree (1) to Strongly Agree (5). The abridged ATMI used in this study measured attitudes towards mathematics under the following dimensions:

1. Self-confidence is designed to measure students' confidence and self-concept of their performance in mathematics. Examples of self-confidence statements that students were asked to agree or disagree with included 'I am able to solve mathematics problems without too much difficulty' and 'studying mathematics makes me feel nervous'.

2. Value of mathematics measures students' beliefs on the usefulness and value of mathematics in their lives now and in the future. Examples of value statements that students were asked to agree or disagree with included 'mathematics is important in everyday life' and 'mathematics is one of the most important subjects for people to study'.

3. Enjoyment of mathematics measures the degree to which students enjoy working with mathematics and their enjoyment in mathematics classes. Examples of enjoyment statements that students were asked to agree or disagree with included 'I have usually enjoyed studying mathematics in school' and 'I am happier in a maths class than in any other class'.

A further scale was included in the questionnaire to determine the extent to which teachers are implementing the Project Maths curriculum as intended. It was decided to employ a scale designed 
by Swan [19], since it accurately captures the phenomenon that is Project Maths. Fifteen items were included that are specifically concerned with student experiences with teaching practices. These items are categorised as 'teacher centred' and 'student centred'. 'Teacher centred' practices are those that are typically associated with transmissionoriented behaviorist teaching practices, in which the teacher directs the work, organizes the material, gives clear instructions, teaches everyone at once in a predetermined manner and emphasizes practice for fluency over discussion for meaning [19].

'Student centred' practices are associated with constructivist learning and implies that the teacher takes students' knowledge and mistakes into account when deciding what to teach, treats the students as individuals as opposed to homogenous blocks, is selective and flexible about what to teach, and allows the students to make decisions, compare different methods and create their own methods [19]. In order to probe deeper into students' prior experiences of mathematics in school, several open-ended questions were also included at the end of the questionnaire. The open-ended responses were transcribed and coded using thematic analysis in order to determine common themes. The open-ended questions included the following:

1. Did you enjoy second level mathematics? Why/why not?

2. What aspects of Project Maths did you enjoy most?

3. What aspects of Project Maths did you enjoy the least?

4. Overall, do you feel mathematically prepared for your higher education course?

\section{Results}

Of the 46 students who completed the questionnaire, 41 had completed the Project Maths curriculum and 5 of these 41 participants completed the higher level Project Maths curriculum. On a 5point scale, the mean score for 'Value of mathematics' for all participants was 3.74 (standard deviation .602), the mean score for 'Enjoyment of mathematics' was 3.42 (standard deviation .585) and the mean value for 'Self-confidence in mathematics' was 3.49 (standard deviation .584). The overall mean ATMI score for all participants was 3.55 (standard deviation .458) indicating a strong attitude towards mathematics to date.

This particular study is principally concerned with participants who experienced the Project Maths curriculum. Therefore, it was decided to examine whether the five participants who completed the Higher level Project Maths curriculum have more positive attitudes towards mathematics. In the results that follow, the reader is reminded that the calculations were completed with a subgroup of five students compared to a group of 41 students who completed the ordinary level curriculum. Overall, only $10 \%$ respondents rated value of mathematics at less than 3.0, and given that the participants are all engineering students, and that engineering is predominantly mathematics based, this suggests that $93 \%$ of the respondents appreciate the value of mathematics to their discipline. $66 \%$ enjoy mathematics more and $78 \%$ feel more confident in their mathematical ability. The overall mean ATMI score for participants who completed the ordinary level curriculum was 3.48 (standard deviation .468), while for participants who completed the higher level curriculum 3.87 (standard deviation .259). This would suggest that participants who completed the higher level curriculum have more positive attitudes towards mathematics, however, a Mann-Whitney U test reveals non-significant differences between the two groups $(\mathrm{p}=.069$, Mann-Whitney $\mathrm{U}=44.5, \mathrm{Z}=$ 1.813).

Examining the individual ATMI factors, the mean score for value of mathematics for participants who completed the ordinary level Project Maths curriculum was 3.63 (standard deviation .622), while for the higher level participants was 3.96 (standard deviation .403). The results of the Mann-Whitney U test also reveals that no relationship exists between prior level of study and value of mathematics ( $\mathrm{p}=$ .202, Mann-Whitney $U=57.5, Z=1.29$ ). The mean score for enjoyment of mathematics for ordinary level participants was 3.37 (standard deviation .621), while for higher level participants was 3.72 (standard deviation .319). The results of the Mann-Whitney U test also reveals that no relationship exists between prior level of study and enjoyment of mathematics ( $p$ $=.162$, Mann-Whitney $\mathrm{U}=54.5, \mathrm{Z}=1.42$ ). The mean score for self-confidence in mathematics for ordinary level participants was 3.43 (standard deviation .541), while for higher level participants the mean self-confidence score was 3.95 (standard deviation .446). In this case, the results of the MannWhitney $U$ test reveals a significant relationship between prior level of study and self-confidence in mathematics ( $\mathrm{p}=.027$, Mann-Whitney $\mathrm{U}=35.5, \mathrm{Z}=$ 2.18).

The questionnaire also explored the kinds of mathematical activities that were typically encountered in mathematics class. Table 1 indicates these mathematical activities while the first column in the Table 2 indicates whether these activities are more student-centered (S) or teacher-centred (T). Student-centred teaching practices are reported as having the potential to engage a more academically diverse student body than the traditional teachercentered approach [19]. Teacher-centred approaches are typically associated with transmission style pedagogy in contrast to student-centred approaches which foster discussion, collaboration and inquiry. The initial analysis indicates that students agree that 
teacher practices are mostly transmission-oriented, an approach not advocated by the Project Maths curriculum. The items in Table 2 have been rank ordered from those most commonly reported to those least commonly reported. In doing this, the studentcentred items reported as being less commonly experienced by students.

\section{Table 1. Teaching practices items}

\section{No. Statement}

1 Told us which question to do

2 Showed us which methods to use and then asked us to use it

3 Asked us to work through practice exercises

$4 \quad$ Let us choose which questions to do

5 Tried to prevent us from making mistakes by explaining things carefully

6 Expected us to follow the textbook or worksheet closely

$7 \quad$ Let us invent our own methods

8 Asked us to work in pairs or small groups

9 Expected us to work mostly on our own, asking a neighbour from time to time

10 Expected us to learn through discussing our ideas

11 Showed us just one way of doing each question

12 Jumped between topics as the need arose

13 Asked us to complete different methods for doing questions

14 Encouraged us to discuss mistakes

15 Showed us how different maths topics link together

Table 2. $T=$ Teacher-centred statement, $S=$ Studentcentred statement and the mean value for each practice: 1 almost never to 5 almost always. Statements are rank-ordered separately from most to least common reported practice

\begin{tabular}{llll}
\multicolumn{2}{c}{ The teacher ..... } & Mean & Std_dev \\
$\mathrm{T}$ & Statement 1 & 4.31 & .874 \\
$\mathrm{~T}$ & Statement 2 & 4.13 & 1.036 \\
$\mathrm{~T}$ & Statement 3 & 4.13 & .919 \\
$\mathrm{~S}$ & Statement 4 & 4.11 & 1.191 \\
$\mathrm{~T}$ & Statement 5 & 3.96 & 1.043 \\
$\mathrm{~T}$ & Statement 6 & 3.91 & 1.104 \\
$\mathrm{~S}$ & Statement 7 & 3.82 & 1.319 \\
$\mathrm{~S}$ & Statement 8 & 3.44 & 1.324 \\
$\mathrm{~T}$ & Statement 9 & 3.27 & 1.338 \\
$\mathrm{~S}$ & Statement 10 & 3.04 & 1.348 \\
$\mathrm{~T}$ & Statement 11 & 2.96 & 1.381 \\
$\mathrm{~S}$ & Statement 12 & 2.89 & 1.133 \\
$\mathrm{~S}$ & Statement 13 & 2.64 & 1.228 \\
$\mathrm{~S}$ & Statement 14 & 2.47 & 1.198 \\
$\mathrm{~S}$ & Statement 15 & 2.33 & 1.225
\end{tabular}

It was suggested by Swan [17], that rather than looking at the items individually, it is more helpful to devise a scale of 'teacher centredness' using the statements in table 2. To do so, Swan states that the student-centred items are reverse coded and added to the ratings for the teacher-centred items. The higher the cumulative score, the more teacher-centred the classroom practices. The total score ranges from 15 to 75 . It is apparent from table 3 that only $12 \%$ of the participants reported teaching practices as studentcentered and $15 \%$ reported a mixture of both studentcentered and teacher-centered practices. This would suggest that Project Maths is not being implemented in the spirit in which it was intended.

Table 3. Teacher-centered scale and frequency of Occurrences

\begin{tabular}{|l|l|l|l|}
\hline Range & Practice & N & Frequency \\
\hline $15<35$ & Student-centered & 5 & $12 \%$ \\
\hline $35<55$ & Mixed & 6 & $15 \%$ \\
\hline $55<75$ & Teacher-centered & 30 & $73 \%$ \\
\hline
\end{tabular}

The internal consistency of both scales was also established. The Cronbach's alpha for the ATMI scale was 0.791 and for Swan's scale was 0.711 , and so both scales are deemed reliable.

The first open-ended question enquired whether students enjoyed mathematics at school and to state a reason why or why not. Of the 41 respondents who experienced the Project Maths curriculum, 34 provided a response to this question. Of these 34 respondents, 20 participants responded with no and the remaining 14 participants responded with yes. The most commonly cited reason for not enjoying mathematics was because of the teacher, while the most commonly cited reason for enjoying mathematics was also because of the teacher. All five participants who completed the higher level Project Maths curriculum responded with yes and cited having a good teacher as the primary reason for enjoying mathematics. Three of the participants who completed the ordinary level curriculum stated that they enjoyed mathematics after moving from the higher level curriculum to the ordinary level curriculum with one participant reporting that 'higher level was too stressful'. The negative responses reported the teachers as 'being not great' for example, while one participant who stated that they enjoyed mathematics because of their teacher reported their teacher as 'very helpful'.

It was apparent from the responses to the second open-ended question that the question lacked clarity. The question enquired about the aspects of the Project Maths curriculum that participants enjoyed most. Project Maths is a collaborative approach to learning mathematics which promotes teamwork, real-world problem solving, communication within the classroom and a shift in the role of the teacher from the transmitter of knowledge to facilitator of learning. It was envisaged that participants would 
respond citing at least one of these as their reason for enjoying mathematics. However, 14 responded with particular topics, for example 4 stated that they enjoyed probability and statistics, while 4 stated that they enjoyed algebra and 6 stated that they enjoyed trigonometry. However, 7 participants stated that they enjoyed real world problems with one participant stating that 'it made maths real'.

It was also quite apparent that the question which inquired about the aspects of Project Maths that participants enjoyed least also lacked clarity. Some participants named particular topics, for example 5 participants stated that they least enjoyed probability and statistics and 3 stated that they did not enjoy algebra. However, nine of the 41 participants stated that the nature of the real world problems and in particular the wording of the questions was the primary reason for not enjoying mathematics. One participant reported that questions were too 'wordy' and 'you have to look for the numbers in the question', and another participant who reported having dyslexia stated that the nature of the questions presented many problems.

Of the 34 participants who answered the question regarding mathematical preparedness for higher education, 15 reported feeling not prepared while 19 participants reported feeling well prepared. The 5 participants who completed the higher level curriculum all reported feeling mathematically prepared for their higher education course. Four participants who completed the ordinary level curriculum stated that having additional 'grinds' or revision courses, aided in their mathematical preparedness for higher education. Two participants who completed the ordinary level curriculum stated that they did feel mathematically prepared for higher education as a result of having repeated the Leaving Certificate examination. Two participants who reported not feeling mathematically prepared for higher education stated that they did not know what to expect in higher education and three participants specifically named the Project Maths curriculum as the reason they did not feel mathematically prepared for higher education.

\section{Discussion}

The purpose of this study was to determine whether Project Maths has had a positive impact on student attitudes towards mathematics for a group of first year engineering students in a third level institution. It is quite apparent that Project Maths is having a positive impact in terms of students valuing mathematics more with $93 \%$ of participants reporting positive attitudes towards value of mathematics. However, $46 \%$ of participants reported not enjoying mathematics, and the most commonly cited reason was the nature of the real world questions and in particular the language used in presenting these questions. $78 \%$ of participants reported high levels of self-confidence in their mathematical ability. It was also apparent that students who completed the higher level mathematics curriculum tended to be more selfconfident in their mathematical ability and tended to feel more mathematically prepared for higher education in comparison with students who completed the ordinary level curriculum.

With only $12 \%$ of participants in this study reporting teaching practices as purely studentcentred, it would appear that teacher-centred pedagogies are still predominantly used in Irish classrooms even after the introduction of Project Maths. $73 \%$ of participants agree that teaching practices are very much 'teacher-centred'. This may be attributed to the difficulties associated with the teacher having to assume a new identity as a facilitator of learning rather than a transmitter of knowledge or the prominent role that the Irish Leaving Certificate examination plays as selection purposes to higher education. While the traditional teacher-centred approach emphasizes the role of the teacher as the transmitter of knowledge, studentcentred teaching imparts the onus on the participants to become involved in their own learning. The facilitator's role is to introduce the subject of discussion, encourage sharing of perspectives and ideas and integrate students' shared experiences. It is evident from this study that teachers are experiencing difficulties in transitioning to their new role. A further $15 \%$ reported teaching practices as a mixture of both student-centred and teacher-centred, and perhaps using a mixture of both methods is better as the learners would be able to enjoy the benefits of both approaches. Instead of becoming dis-interested with a purely teacher-centred approach or losing sight of their goals in a completely student-centred approach, learners could benefit from a wellbalanced educational environment combining both approaches.

Selection to higher education in Ireland is based on the points system and the Irish Leaving Certificate examinations which is considered a high stakes examination. Students are awarded points based on six out of seven subjects and points are awarded based on grades and the level with which the subject was completed (higher versus ordinary versus foundation). The maximum number of points achievable in the Irish Leaving Certificate is 600 points. The higher level mathematics curriculum tends to be more time-consuming and uptake of higher mathematics can be low, each year approximately 2,000 students who start out with ambitions to undertake the higher level paper drop to ordinary level in the months before the Leaving certificate examination. In order to address this issue and to encourage the uptake of higher level mathematics, the Irish Government introduced an initiative of awarding an additional 25 extra bonus 
points to anyone who completed the higher level mathematics curriculum. However, this study revealed that three participants felt that the higher level curriculum was too 'stressful', these particular participants dropped to the Ordinary level curriculum. The fact that only $12 \%$ of participants reported teaching practices as student-centred support what [7] stated, that when education is driven by significant focus on results and achievement, adopting constructivist approaches can be difficult, and traditional methods are normally seen to deliver results. This could offer a possible insight into why teachers in post-primary education are experiencing difficulties in implementing the principles espoused by the Project Maths curriculum.

It is also evident from the response to the first open-ended question, that the teacher is influential in determining whether students enjoy mathematics or not. Teachers are instrumental in creating active and positive learning environments and, by demonstrating an enjoyment and appreciation of mathematics themselves, teachers can encourage a positive attitude towards mathematics in students. Teachers inevitably face many challenges in the classroom including the wide range of abilities, large class sizes, lack of support or resources and time constraints. Perhaps one of the biggest obstacles that many teachers encounter is how to instil in students an appreciation and love of mathematics.

\section{Conclusion}

It is apparent from this study that Project Maths is having a positive impact on student attitudes towards mathematics. While students generally enjoy mathematics and feel reasonably more confident in their mathematical ability, it is evident that they are more appreciative of the value of mathematics for their future careers. It is also quite apparent that students who completed the higher level curriculum tend to feel more mathematically prepared for higher education. The fact that three of 41 participants dropped to the ordinary level curriculum requires further investigation. The Irish government anticipated that the introduction of Project Maths would result in more students pursing higher level mathematics, however this study revealed that $7 \%$ of participants dropped the higher level curriculum as it was deemed too stressful. This could be investigated further by administering the questionnaire to a larger population from a wider variety of academic disciplines to determine if other students experienced similar issues. It was also clearly evident that an equal number of students enjoy real world problem solving, however, this study does highlight that more needs to be done in order to ensure that for students whereby English is not their spoken language and for those who are maybe dyslexic, that Project Maths does not disadvantage them in any way.
This study had several limitations, and since engineering is generally considered a male dominated discipline, the fact that only one female participated is not surprising but is a limitation. However, to address gender balance, the questionnaire could be administered to a large body of undergraduate participants from a wide range of disciplines including science, engineering, computing, business, accountancy and nursing which has the added advantage of increasing sample size. The face validity of the open-ended questions (Q2 and Q3) was also compromised, however the researcher can take steps to address this concern in any future studies. For example in Q2, participants may be presented with a list of the five aspects underpinning the Project Maths curriculum of which they must select the aspect that they enjoyed most, least and to elaborate with their reasoning.

In order to understand participants' perceived mathematical preparedness for higher education, instead of requesting participants to specify whether they felt mathematically prepared based on a yes/no response, a 4 point scale with 1 - not at all prepared, 2 - slightly prepared, 3 - well prepared and 4 extremely well prepared could be used. Participants could also be required to present two reasons for their perceived level of preparedness. Asking the question in this manner has the potential to provide much greater detail and will enable the researcher to probe the issue of mathematical preparedness further.

This study could also be extended to include focus group discussions in order to gain a deeper understanding of students' experiences of Project Maths in school. Focus groups have the potential to provide a vast amount of information on students' shared experiences and are particularly useful in obtaining several perspectives in a short period of time. Focus groups are particularly useful when trying to determine what the shared understanding of a particular topic is and have the potential to go a step beyond the open-ended responses used in the survey. Focus groups also have the potential to increase the validity and creditability of the research findings. The topics of discussion for the focus group could be selected based on the responses to the openended questions within the survey. In the case of this study, focus groups could probe further into the reasons why three of the forty one participants dropped the higher level curriculum in favour of the ordinary level curriculum as well as addressing the issue of clarity in some of the open-ended questions.

\section{References}

[1] National Council for Curriculum and Assessment (NCCA) (2005). 'Review of Mathematics in Post-Primary Education - a discussion paper'; http://www.ncca.ie/ uploadedfiles/MathsReview/MathsDiscusPaperEng.pdf (Access Date: 17th April 2014) 
[2] Cosgrove, J., Perkins, R., Shiel, G., Fish, R., and McGuinness, L. (2012) 'Teaching and Learning in Project Maths Insights from teachers who participated in PISA 2012';http://www.ncca.ie/en/Conference/Teaching_and_L earning_in_Project_Maths_Web_Report.pdf (Access Date: $1^{\text {st }}$ September 2015).

[3] O'Donoghue, J., (2002). 'Mathematics: transition from second level to university'. Fr. Ingram memorial Lecture to the Irish Mathematics Teachers Association, Waterford Institute of Technology.

[4] Lynch, B. (2011). Towards an Instructional Model to support Teaching and Learning in Mathematics. Paper presented at the Fourth Conference on Research in Mathematics Education MEI4, St. Patrick's College, Drumcondra, Dublin 9.

[5] Petersen, P. L., (1988). Teachers' and students' cognitional knowledge for classroom teaching and learning. Educational Researcher, 17(5), pp. 5-14.

[6] Desforges, C. and A. Cockburn, (1987). Understanding the Mathematics Teacher. Sussex: Falmer Press.

[7] Brooks, J. G., and Brooks, M. G. (2001). 'Becoming a constructivist teacher'. In Costa, A.L. (Ed.), Developing minds: A resource book for teaching thinking (3rd ed., pp. 150-157). Alexandria, VA: Association of Supervision and Curriculum Development.

[8] Fensham, P. J. (1992). 'Science and technology'. In: Jackson, P.W. (ed.), Handbook of research on curriculum. New York: Macmillan, pp. 789-829.

[9] Atkin, J.M. and Helms, J. (1993). Getting Serious About Priorities in Science Education, Studies in Science Education, 21, pp. 1-20.

[10] Grootenboer, P., and Hemmings, B. (2007). Mathematical performance and the role played by affective and background factors. Mathematics Education Research Journal, 19(3), 3-20.

[11] McLeod, D.B. (1992). 'Research On Affect in Mathematics Education: A Reconceptualisation', In: Grouws, D.A., Handbook of Research on Mathematics Teaching and Learning, New York, Macmillan.

[12] Liston, M. and O'Donoghue J., (2007) 'The Transition from Secondary School Mathematics to University Mathematics'; www.leeds.ac.uk/educol /documents/167980.doc (Access Date: $7^{\text {th }}$ March 2016)

[13] Owens, K., Perry, B., Conroy, J., Geoghegan, N. and Howe, P. (1998). 'Responsiveness And Affective Processes In The Interactive Construction Of Understanding In Mathematics', Educational Studies in Mathematics, 35(2), pp. 105-127.

[14] Kayander, A. and Lovric, M. (2005). Transition From Secondary to Tertiary Mathematics: McMaster University experience, International Journal of Mathematical
Education in Science and Technology, 36(2-3), pp. 149160.

[15] Philipp, R. A. (2007). Mathematics teachers' beliefs and affect. In Lester, F.K. (Ed.), Second handbook of research on mathematics teaching and learning (pp. 257315). Charlotte, NC: Information Age Publishing.

[16] Di Martino, P. and Zan, R. (2010). 'Me and maths': towards a definition of attitude grounded on students' narratives. Journal of Mathematics Teacher Education, 13 (1), pp. 27-48.

[17] Taat, M. and De Rozario, G. (2014) The influence of academic attitude and self-efficacy towards students' achievement in private higher learning institution, Malaysia, International Journal of Arts and Commerce, 3 (6), pp. 41-50

[18] Tapia, M. (1996) 'The Attitudes Toward Mathematics Instrument'. Paper presented at the annual meeting of the Mid-South Educational Research Association, Tuscaloosa, AL; http://eric.ed.gov/?id=ED404165 (7/3/2015)

[19] Swan, M. (2006). Designing and using research instruments to describe the beliefs and practices of mathematics teachers. Research in Education, 75, pp. 5870.

[20] Hockings, C. 2009. Reaching the students that student-centred learning cannot reach. British Educational Research Journal 35, pp. 83-98.

[21] Bielenberg, K. (2013). 'New Project Maths course causes multiple divisions'. The Independent, $20^{\text {th }}$ March, http://www.independent.ie/lifestyle/education/new-projectmaths-course-causes-multiple-divisions-29143498.html (Access Date: 9th April 2017)

[22] Gath, E. (2012). 'Project Maths is not the answer to tough question'. The Irish Examiner, March 21 ${ }^{\text {st }}$, http://www.irishexaminer.com/analysis/project-maths-isnot-the-answer-to-tough-question-187777.html (Access Date: 17th February 2017)

[23] Ernest, P. (2013). The Psychology of Mathematics, Amazon, Kindle.

\section{Acknowledgements}

Thanks are extended to the students who willing gave their time to respond to the questionnaire. 